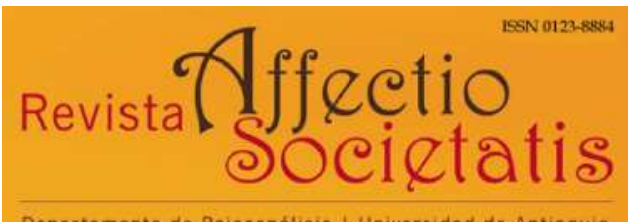

Departamento de Psicoanálisis I Universidad de Antioquia

Revista Affectio Societatis

Departamento de Psicoanálisis

Universidad de Antioquia

revistaaffectiosocietatis@udea.edu.co

ISSN (versión electrónica): 0123-8884

Colombia

2019

Elton Augusto Pinotti e Souza

O PROBLEMA DA EXPERIÊNCIA DO SER EM HEIDEGGER E LACAN

Revista Affectio Societatis, Vol. 16, N. ${ }^{0}$ 30, enero-junio de 2019

Art. \# 3 (pp. 63-82)

Departamento de Psicoanálisis, Universidad de Antioquia

Medellín, Colombia 


\title{
O PROBLEMA DA EXPERIÊNCIA DO SER EM HEIDEGGER E LACAN ${ }^{1}$
}

\author{
Elton Augusto Pinotti e Souza² \\ Instituto de Psicologia da Universidade de São Paulo, Brasil \\ eltonpin@gmail.com \\ ORCID: 0000-0002-9528-9614
}

DOI: 10.17533/udea.affs.v16n30a03

\section{Resumo}

$\mathrm{O}$ artigo aborda a relação entre ser e linguagem nas obras de Heidegger e Lacan. Para tanto,fizemos um percurso de diálogo crítico com algumas ideias de Slavoj Žižek presentes no artigo "Por que Lacan não é heideggeriano", enquanto propusemos um problema: o ser só pode surgir pelo logos? Com os conceitos de das Erei- gnis em Heidegger e de gozo suplementar em Lacan, reconhecemos uma possibilidade de experiência do ser para mais além da identidade metafísica ou das identificações da fantasia.

Palavras-chave: Heidegger, Lacan, Žižek, linguagem, ser.

\section{EL PROBLEMA DE LA EXPERIENCIA DEL SER EN HEIDEGGER Y LACAN}

\section{Resumen}

El artículo aborda la relación entre ser y lenguaje en las obras de Heide-

gger y Lacan. Para tal fin, hicimos un recorrido de diálogo crítico con algu-

1 Pesquisa financiada pela Fundação CAPES, Brasil.

2 Psicanalista pós-graduado (nível mestrado) e graduado do Instituto de Psicologia da USP (Departamento de Psicologia Clínica). Intercambista bolsista (Bolsa Mérito Acadêmico USP) na Universidade francesa Université Rennes 2 (Psicopatologia). Foi pesquisador e supervisor clínico do Laboratório de Piscanálise, Saúde e Instituição do Departamento de Psicologia Clínica do IP-USP. Coordenador de comunicação da editora CosacNaify (2007-2008). Graduado em Comunicação Social (ESPM-SP). 
nas ideas de Slavoj Žižek presentes en el artículo "Por que Lacan não é heideggeriano", al tiempo que propusimos un problema: ¿El ser solo puede surgir por el logos? Con los conceptos de das Ereignis en Heidegger y goce suplementario en Lacan, reconocemos una posibilidad de experiencia del ser para más allá de la identidad metafísica o de las identificaciones de la fantasía.

Palabras clave: Heidegger, Lacan, Žižek, lenguaje, ser.

\section{THE PROBLEM OF THE EXPERIENCE OF BEING IN HEIDEGGER AND LACAN}

\section{Abstract}

This paper addresses the relation between being and language in Heidegger and Lacan's works. To that end, we made a journey of critical dialog with some of Slavoj Žižek's ideas present in the article "Por que Lacan não é heideggeriano"; at the same time, we proposed a problem: does the being appear only through the logos? With the concepts of das Ereignis in Heidegger and supplementary jouissance in Lacan, we recognize a possibility of experience of being for beyond the metaphysical identity or the fantasy identifications.

Keywords: Heidegger, Lacan, Žižek, language, being.

\section{LE PROBLÈME DE L'EXPÉRIENCE DE L'ÊTRE CHEZ HEIDEGGER ET LACAN}

\section{Résumé}

Cet article aborde la relation entre être et langage chez Heidegger et Lacan. Dans ce but, l'on a effectué une révision critique de quelques idées de l'article «Pourquoi Lacan n'est pas heideggérien " de Slavoj Žižek, en même temps que l'on posait la question suivante : l'être surgit-il seulement par le logos ? Le concept de das Ereignis chez Heidegger et celui de jouissance supplémentaire chez Lacan, nous mènent à reconnaître une possibilité d'expérience de l'être au-delà de l'identité métaphysique ou des identifications de la fantaisie.

Mots-clés : Heidegger, Lacan, Žižek, langage, être.

Recibido:07/07/2017 • Aprobado:14/05/2018 


\section{Introdução}

A diferença em relação a Heidegger é que Lacan, ao invés de aceitar esse acordo (mesmidade) entre Ser e lógos, tenta sair dela, para uma dimensão do real indicada pela junção impossivel entre sujeito e gozo.

Žižek. "Por que Lacan não é Heideggeriano".

Trata-se aqui da questão da experiência do ser em relação à linguagem, a partir dos pensamentos de Heidegger e de Lacan. Questionaremos primeiramente o artigo "Por que Lacan não é heideggeriano" (2009) de Slavoj Žižek, texto em que somos apresentados à hipótese de que a grande separação teórica entre Heidegger e Lacan residiria justamente no problema da equivalência ou diferenciação do ser diante da linguagem. As várias análises de Žižek derivam ali de dois pilares: 1. em Heidegger, ser é o mesmo que linguagem (ou logos) - isto é, a ideia de que o ser tanto se abre quanto se manifesta enquanto linguagem -, ao passo que, 2 . Lacan teria superado um acordo mútuo entre pensamento e ser, desde que o ser apontaria agora ao furo Real no âmago não-localizável do sujeito, como uma impossibilidade irredutível não apenas da linguagem como da própria experimentação.

Abordaremos o problema da experiência do ser primeiramente em diálogo com os argumentos de Žižek: Heidegger ensurdecera de fato ao diapasão principal de sua própria inspiração filosófica, fundamentada desde Ser e Tempo (1927) e disseminada ao longo de sua obra, a ideia de uma transcendência do ser em relação ao pensamento, ao homem, ao ente? Ou seja, a manifestação do ser para Heidegger não passaria de um pensar? E por outro lado, seria o conceito lacaniano do objeto a, enquanto o ser inapreensível do sujeito, a única formulação de Lacan para colocar-se em questão o ser do "ser falante" (parlêtre)?

O intuito que assumimos com nosso estudo vai justamente na via de demonstrar o equívoco de uma leitura do sentido do ser em Heidegger em relação de igualdade à linguagem, como uma redução 
perpétua do ser na linguagem ou enquanto pensamento. Queremos sobretudo retomar a ideia de que não é meramente por teorizar que o ser é impensável - isto é, real - que Lacan teria arquitetado uma saída do acordo filosófico entre logos e ser. Pensaremos aqui na legitimidade de uma escuta clínica aberta à possibilidade de experiência de gozo - ou experiência de ser - que excede a mônada simbólica do sujeito, ideia que entraria para o cerne da psicanálise pelo conceito de "gozo feminino", mesmo que de modo incontornavelmente polêmico e obscuro.

\section{O ser que não é igual ao logos em Heidegger}

Primeiramente, se criticamos o ponto zero do artigo de Žižek sobre Heidegger - a denunciada indiferenciação entre ser e linguagem -, nossa intenção não é a de discutir nem refutar toda a sequência argumentativa que dali se desencadeia, isto é, não é nosso objetivo deslegitimar a queda de um primeiro dominó para recuperar todo o eixo das demais peças (neste caso, as diversas consequências políticas da negação da subjetividade em Heidegger). O diálogo com o artigo de Žižek nos servirá apenas como um ensejo à análise da questão da experiência do ser na obra de Heidegger e Lacan.

Em seu artigo, Žižek recupera a famigerada afirmação de Heidegger - a linguagem é a casa do ser - para sugerir um avanço teórico de Lacan efetuada na proposição: a psicanálise devia ser a ciência da linguagem habitada pelo sujeito (Žižek, 2009). Mais do que isso, assumindo uma posição epistemológica lacaniana, Žižek não hesita em interpretar Heidegger a partir dos conceitos psicanalíticos; e assim é que, em poucas palavras, haveria Heidegger indiferenciado Simbólico de Real. A afirmação supracitada está em Carta sobre o Humanismo, de 1983:

A linguagem é a casa do ser. Nesta habitação do ser mora o homem. Os pensadores e os poetas são os guardas desta habitação. A guarda que exercem é o consumar a manifestação do ser, na medida em que a levam à linguagem e nela a conservam. (Heidegger, 1983/1949, p.149). 
O ser ter acesso à linguagem significaria, portanto, que a linguagem seria tanto a moradia quanto o modo de manifestação do ser. Mas nesse caso, o que viria a dizer levar o ser à linguagem, se entre os dois, ser e linguagem, não há separação ou diferença alguma? Pois se a tese for a da linguagem como única sustentação do ser, para Žižek, a síntese dos anjos entre pensamento e ser teria sido superada com Lacan, que:

(...) foca o real do gozo como algo que, embora esteja longe de ser simplesmente externo à linguagem (é antes "êx-timo" em relação a ela), resiste à simbolização, permanece um caroço estrangeiro em seu interior, aparece nela como uma ruptura, corte, hiância, inconsistência ou impossibilidade. (Žižek, 2009).

De fato, a ideia que em Lacan está tão explícita - a impossibilidade de simbolização do ser -permaneceria totalmente ausente ou no melhor dos casos ambígua se nos atermos somente às passagens supracitadas de Heidegger. E para avançarmos nessa questão, consideremos de antemão uma rápida introdução do problema do ser na analítica existencial.

A questão sobre o sentido do ser perdeu-se, segundo Heidegger, ao longo da história da metafísica enquanto tradição da filosofia ocidental e mais especialmente nas ciências modernas, na medida em que a interrogação praticada por tais disciplinas resumiu-se exclusivamente ao ente, ao âmbito das evidências, ou seja, à investigação da objetividade "real" dos existentes dados à percepção. A ideia é que algo do ser estaria perdido na medida em que se apreende o ser como "algo". E para apontar o que restou como o esquecido das metafísicas, Heidegger desafiaria as ciências, de modo um tanto irônico, por exemplo, a responder onde estaria, nos campos das teorias do estímulo sensorial, o "é" de cada ente averiguado: "Nem mesmo o maior acúmulo e intensidade possíveis de estímulos fazem aparecer o "é". Em todo ser estimulado o "é" já aparece pressuposto" (Heidegger, 2006, p.201); e, mais gravemente do que pressuposto, esquecido e impensado em tal pressuposição, como um resto invisível e destinado à invisibilidade.

Boa parte da tradição filosófica teria entendido também por "problema do ser" a pergunta pelo ente (Heidegger, 1969/1955, p. 11). Por 
consequência, efetuar-se-ia um equívoco investigativo desde o modo de se colocar a questão, pressupondo-se o ser em equivalência ao ente manifestado. Ocorre que a razão de tal pressuposição não seria arbitrária. Em Ser e tempo (2009/1927), Heidegger afirma que alguma compreensão de ser no Dasein - o ser humano, como único ente dotado da possibilidade de questionar-se sobre o ser - já estaria sempre incluída em tudo o que se apreende do ente. Numa concepção prévia, o ser das coisas existentes se ocultaria numa suposta evidência própria da manifestação de cada uma delas - na constatação imediata de que "cada coisa simplesmente é" -, como aquilo pelo o que não se precisaria nem mesmo interrogar. Para Heidegger, o conceito de ser, em virtude de sua ocultação na pré-compreensão do Dasein, seria a questão mais obscura e enigmática para o pensamento (Heidegger, 2009/1927, p.39).

Primeiramente, Heidegger entende que o fundamento da metafísica consiste no esquecimento do ser no interior da evidência do ente (no ôntico da ek-sistência). A questão que surge a partir disso, presente na leitura de Žižek, seria a de que Heidegger haveria fundamentado uma separação ontológica entre ser e ente, mas resguardando o ser na ordem de uma determinada manifestação na linguagem, suportada e em correspondência ao logos.

Mas ocorre dessa equivalência receber diversos contrapontos nos próprios escritos de Heidegger. Vejamos por exemplo em Identidade e diferença (1983/1957):

A metafísica corresponde ao ser enquanto lógos (...) Na medida em que a metafísica pensa o ente enquanto tal, no todo, ela representa o ente a partir do olhar voltado para o diferente da diferença (isto é, a indiferença/igualdade), sem levar em consideração a diferença enquanto tal. O que assim é designado remete nosso pensamento para o âmbito que não pode mais ser dito pelas palavras-guias da metafísica, ser e ente, fundamento-fundado. (...) A origem da diferença [entre ser e lógos] não mais se deixa pensar no horizonte da metafísica. (p.200, itálico nosso).

(...) Se alguma superação (da metafísica) permanece necessária, então interessa aquele pensamento que propriamente se insere no Ereignis, para dizê-lo a partir dele e em direção a ele. (p.271, itálico nosso). 
Segundo Heidegger, pensador da "superação da metafísica", é a própria diferença entre ser e logos que permaneceria impensada, ou diríamos excluída do campo perceptivo da metafísica, tal qual um ponto cego. A equivalência (ser=logos) caracterizaria o próprio modo de ser da metafísica - constituída numa sólida e constante alienação da diferença entre pensar e desvelar o ser. Haveria aí uma denúncia sobre a cegueira congênita e própria do homem entregue à metafísica do ser, "no todo" ele aderido ao logos. E se a indiferença entre ser e logos é o que aguardaria uma superação, Heidegger sugere insistentemente que a saída de tal labirinto dar-se-ia mediante outro estado de coisas, um misterioso acontecimento-apropriador denominado por ele de Das Ereignis - experiência que "não pode mais ser dito pelas palavras guias da metafísica". Uma pessoa despertada pela Ereignis experimentaria uma armação tempoespacial da realidade bastante incomum, por assim dizer.

O problema parece sutil, mas é de grande peso: superar o pensamento metafísico seria simplesmente pensar diferente (simbolizar, quem sabe elaborar mais adequadamente o ser), ou haveria algo a mais nessa experiência (Erfahrung) de viragem para além dos limites da metafísica? Vejamos essas passagens das conferências de "Tempo e ser" (1983/1962):

No transcurso do seminário, falou-se repetidas vezes de experimentar [Erfahren]. Assim, entre outras coisas, se disse: $\mathrm{O}$ despertar no interior do Ereignis deve ser experimentado, não pode ser demonstrado. Uma das últimas questões levantadas referiu-se ao sentido deste experimentar. Viu-se uma certa contradição no fato de o pensamento mesmo dever ser a experiência do estado de coisas, sendo, ou outro lado, apenas a preparação da experiência. Portanto, assim se concluiu, o pensamento (também o pensamento que foi tentado no próprio seminário) não é ainda a experiência (...) Assim, o despertar dentro do Ereignis permanece algo que deve ser experimentado, mas justamente enquanto tal, algo que primeiro está necessariamente ligado ao despertar do esquecimento do ser para o Ereignis. Permanece, portanto, primeiro, um acontecer que deve ser mostrado e deve sê-lo. ${ }^{3}$ (p.292, itálico nosso).

3 Trata-se de um trecho do protocolo da sexta sessão do seminário "Tempo e ser" proferido por Heidegger, redigido por Alfredo Guzoni. O seminário ocorreu Todtnauberg, de 11 a 13 de setembro de 1962. 
E de "Identidade e diferença" (1983/1957): Trata-se de simplesmente experimentar este ser próprio de, no qual homem [linguagem, logos, ente] e ser, estão reciprocamente a-propriados, experimentar que quer dizer penetrar naquilo que designamos acontecimento-apropriação [Ereignis] (p.185).

O que se lê nessas passagens é que, meramente pensar na Ereignis (o desvelamento do ser) não é ainda a própria experiência de apropriação do ser, vivenciada necessariamente como singulare tantum: única e irrepresentável. Para Heidegger, o ser permaneceria velado e inconcebível (enquanto experiência viva) para o alcance do reconhecimento metafísico, capaz apenas de pensar o ser enquanto um conceito (logos) dado na oposição sujeito-objeto, ora tomado como positividade (ser=algo), ora como negatividade (ser=nada). Consideremos que a ponderação que um daltônico faça sobre a cor vermelha (pensar que haja uma diferença em relação à cor verde) não corresponde em nada à experiência viva do vermelho. O exemplo é evidentemente grosseiro, pois a percepção de uma nova cor diria respeito ao desvelamento de uma inédita qualidade de um ENTE qualquer, e não a irrupção do SER que se vela no Dasein em diferença a qualquer ente. Mas basta que consideremos que para Heidegger o evento de desvelamento do ser não corresponde ao evento de pensar no desvelamento do ser, ou seja, que não seria no domínio do logos que o ser irromperia numa "singular estranheza" (Heidegger, 1969/1955, p.49). Conclui-se disso que a Ereignis permaneceria impensável, portanto? "Fazer uma colocação sobre a linguagem não significa tanto conduzir a linguagem, mas conduzir nós mesmos para o lugar de seu modo de ser, sua essência: recolher-se no acontecimento-apropriador [Ereignis]" (Heidegger, 2003/1959, p.8).

Vejamos ainda algo sobre a "riqueza velada da linguagem". Diz-nos Heidegger em “A essência da linguagem" (2003/1959): “Talvez na palavra "caminho", Tao, resguarde-se o mistério [Geheimnis] de todos os mistérios da saga pensante do dizer, ao menos quando deixamos esses nomes retornarem para o que neles se mantém impronunciado [Ungesprochene]" (p. 155, itálico nosso).

No acontecimento-apropriação [Ereignis] vibra a essência [schwingt das Wesen] daquilo que a linguagem fala, a linguagem que certa vez designamos como a casa do ser (Heidegger, 1983/1957, p.186, itálico nosso). 
Se em Heidegger o ser "mora" na linguagem, "vibra" também para além dela. A "vibração da essência" (die Schwingung des Wesen), que se desvela com a experiência da Ereignis, permanece indizível (Ungesprochene) e, paradoxalmente, revela-se como a própria essência da linguagem (Das Wesen der Sprache). Apesar de Heidegger fundamentar a Ereignis (o ser) num inefável - a "conformação do quieto da linguagem", o "mostrar o lugar da poesia impronunciada" (Heidegger, 2003/1959, p.29) -, sugere ao mesmo tempo uma possibilidade de se corresponder à "vibração" do ser do Dasein em seu dizer, caso isso se dê no "interior" de tal experiência.

Não se pode concluir disso nem que o logos desvele o ser, tampouco que a linguagem tomada pela Ereignis represente finalmente o ser. Menos ainda que o testemunho da Ereignis transmita a abertura do ser para o despertar e deleite alheio (retire da Ereignis sua condição ontológica de singulare tantum). A obscuridade proto-poética de Heidegger, assim, não justificaria a ideia de que se houvesse assumido uma equivalência (mesmidade em sentido de igualdade) entre ser e logos, como quer Žižek, ao afirmar que:

(...) até Heidegger, o Ser que a filosofia tem em mente é sempre o ser cuja casa é a linguagem, o ser sustentado pela linguagem, o ser cujo horizonte é aberto pela linguagem", pois "a premissa básica de Heidegger "como já Parmênides - o primeiro filósofo - o colocou, "pensar e ser são o mesmo", o acordo mútuo entre pensamento (logos como razão/discurso) e ser. (2009, p.12).

A leitura é questionável pois Žižek passa completamente em branco pela vocação paradoxal da mesmidade na obra de Heidegger, cujo sentido se não reduz absolutamente à lógica da igualdade. Heidegger, ao citar precisamente este princípio filosófico de Parmênides - "Pois o mesmo é tanto pensar como ser" -, afirma que "o mesmo, porém, não é o igual. No igual a diversidade desaparece. No mesmo a diversidade se manifesta" (1983/1957, p.190, grifo nosso). A revelação da Ereignis para Heidegger não é outra coisa senão a experiência totalmente incompreensível aos ouvidos do sujeito da metafísica: a diferença radical enquanto diferença entre ser e logos (p.191). A partir disso - e não antes ou depois disso -, a diferença poderia enfim ser pensada, mas permanecendo o ser não-representado neste pensamento. 
A diferença poderia ser pensada, e não o ser. Assim como é possível ao daltônico ponderar sobre a diferença entre os verdes e vermelhos, ao pensamento metafísico é também dada a possibilidade de reflexão sobre a diferença misteriosa entre pensar ser e ser. O problema aqui retoma a muito polêmica questão da espera, da passividade do homem frente ao seu ser esquecido, desde que o ser, de seu posto transcendente, não se deixa convocar ou vibrar pelo pensamento do homem.

\begin{abstract}
Assim apropriado, o homem pertence ao Ereignis (...) A isto se deve o fato de nunca sermos capazes de colocar o Ereignis diante de nós, nem como algo que se opõe a nós, nem como algo que a tudo abarca. É por essa razão que o pensamento que representa e fundamenta corresponde tão pouco ao Ereignis quanto o dizer simplesmente enunciador. (...) Sem dúvida, tornou-se agora visível que o que quer dizer Ereignis, passado pela análise do próprio ser e do próprio tempo, pela penetração do destino do ser e no alcançar do espaço-de-tempo. (...) Que resta dizer? Apenas isto: o Ereignis acontece-apropria. Com isto dizemos, a partir do mesmo, para o mesmo, o mesmo. Aparentemente, isto não diz nada. Realmente não diz nada enquanto ouvirmos o que foi dito como uma simples enunciação, proposição, e o entregarmos ao interrogatório da lógica. (Heidegger, 1983/1962, p.270, itálico nosso).
\end{abstract}

Žižek desconsidera tanto o núcleo inefável da Ereignis quanto todo o campo das transformações do espaço-de-tempo, tudo aquilo que Heidegger sugere se passar como uma alteração apropriadora da temporalidade e da espacialidade da abertura de mundo em Ereignis. Relembra-nos Ernildo Stein, por exemplo, que "o acontecimento-apropriação é essencialmente outra coisa, porque muito mais rico que qualquer determinação metafísica do ser" (Heidegger, 1983/1957, p.185). Em grossíssima expressão, o desvelamento do ser ocorreria mais propriamente numa impensável mutação da realidade vivida, irreduzível a uma atividade simbólica peculiar, isto é, a uma abordagem intelectual mais específica do ser. E no caso de pressionarmos Heidegger contra os conceitos lacanianos, ao modo de Žižek, seríamos desafiados pelo menos a pensar em alterações mais abrangentes da própria amarração imaginária-simbólica (RSI) da experiência diante do real, implicando-se aí desidentificações objetais, e, sobretudo, falaríamos da emergência de uma nova forma de gozo. E se 
reconhecemos o "não-todo" do logos em relação ao ser, também em Heidegger, não seria esse o elemento que separaria tão radicalmente o óleo da analítica existencial da refrescante água lacaniana.

\section{Žižek e Sloterdijk contra a alienação política Heideggeriana}

Sobre a passividade do Dasein em relação ao ser, Žižek aposta todas as suas fichas no sentido alienante de tal projeto. Em $O$ amor impiedoso (2012), o autor acusa as "experiências de Self" de uma precária mentira individual com a qual os seus aspirantes, ao modo de um fetiche, suportariam fantasiosamente uma verdade social insuportável. A visagem de um gozo êxtimo (experiência do ser) adentra no pensamento de Žižek como conivência perversa com as tragédias do capitalismo, pois aquele que encontra "serenidade" em seu ser (refere-se ao conceito heideggeriano, implicado na Ereignis) não passaria de um pusilânime apolítico, um sujeito ausentado da realidade social em razão de jactar-se de um gozo, em si e para si, não além do reduto de sua individualidade.

Žižek associa o pensamento de Heidegger às aspirações dos praticantes do "budismo ocidental"; como duas manifestações culturais de um mesmo fetiche de recusa da participação política:

(...) onde está o fetiche que lhe permite (fingir) aceitar a realidade "como ela é"? O "budismo ocidental" é tal fetiche: ele lhe permite participar integralmente da marcha frenética do jogo capitalista, sustentando a percepção de que realmente você não faz parte dele, de que você está muito ciente do quanto esse espetáculo é sem valor - o que realmente importa a você é a paz de seu Self interior, ao qual você sempre pode se retirar (...). (2012, p.79).

De seu sofá e vidrado na verdade cósmica indelével e Perfeita, o gnóstico espiritualista (ou "budista ocidental") aceitaria qualquer coisa, pois inclusive as grandes barbáries fariam parte da evolução cósmica do ser como sístoles e diástoles entre o Caos e a Harmonia. Pois se Tudo é passageiro e de acordo com Deus, bastaria ao espiritualista aceitar seu papel passivo na paisagem. 
Mas vejamos como a apreciação de Žižek neste caso surge como uma variação sobre o tema crítico do filósofo alemão Peter Sloterdijk, disparada anteriormente mas também contra Heidegger, em Regras para o parque humano, de 1999. Sloterdijk estava interessado em apontar o que há de danoso no desenraizamento biocultural do modelo antropológico de Heidegger, de consequências extremamente alienantes em razão de um esvaziamento do compromisso real do homem (o Dasein) com seus co-habitantes sociais. Em poucas palavras, a fenomenologia existencial seria uma filosofia negligente por exaltar uma minoria incapaz de sustentar um elo social relevante.

Já em Esferas I (2009/1998), Sloterdijk enfoca sua crítica em outro aspecto das experiências místicas (outra expressão para as "experiências de Self"), qualificando-as de ilusão no sentido de operarem uma "regressão psíquica" em seus praticantes. O autor enxerga nos eventos de "unidade" das experiências místicas determinados efeitos de um retorno psíquico às origens placentárias de cada ser humano, às condições não-objetais das experiências pré-natais (p.279). E é nessa chave compreensiva que o autor caracteriza também os possíveis fenômenos "para-metafísicos" implicados na Ereignis heideggeriana uma espécie de suporte filosófico para os anseios tão antigos quanto "regressivos" inerentes às tradições místicas orientais.

Nessa hipótese, a aspiração da Ereignis conduziria o homem à forçosa indiferenciação entre todos os entes, numa espécie de unidade pré-subjetiva bebê-placenta; um princípio de identidade absoluta. A Ereignis receberia aqui a sua interpretação mais descompassada: tratar-se-ia da experiência de Unidade do Dasein no sentido de um estado de pura homogeneidade entre ser e ente, entre Dasein e alteridade, em uma inegável experiência de perda de singularidade.

Duas propriedades da Ereignis ficam desconsideradas nessa interpretação: evento em que se ultrapassa a propensão metafísica de identificar ser enquanto ente - e um objeto, para Heidegger, é essa identidade metafísica entre ser e ente (2002/1950, p.145) -, e evento em que se ultrapassa as identidades do Dasein enquanto um "eu metafísico interno" em contraposição a objetos "externos". Queremos apontar com isso que a interpretação de Sloterdijk também se susten- 
ta na estranha omissão do paradoxo fundamental da fenomenologia heideggeriana: desvelar ser e ente como o mesmo, isto é, como essencialmente diferentes e não-isoláveis. De modo que "reunir e conjugar, numa unidade, as diferenças" (Heidegger, 2002/1950, p.151) não nos parece significar de modo algum uma espécie de blecaute psicótico da experiência de mundo.

Mas que Heidegger tenha deixado pairar o senso histórico do panorama biocultural e subjetivo do Dasein, e que ele, pessoalmente, tenha ou não se envolvido com imperdoáveis controvérsias políticas, isso justificaria uma inteira e generalizada negação ou deslegitimação das experiências "pós-metafísicas"? A suposta vivência de uma Abertura de êxtase frente ao vazio, em que se alteram drasticamente as relações entre linguagem e ser, marcaria uma divisão cirúrgica entre uma minoria apolítica de outra parcela apta ao engajamento social? Há mesmo essa oposição fixa e consistente entre gozo e política, entre ser e desalienação? Assim, como entenderíamos Lacan na ideia de que "a mística, não é de modo algum tudo aquilo que não é a política"? (Lacan, 2008, p.82)

\section{Um ser mais além do objeto a}

Consideramos a leitura de Žižek duplamente problemática. Primeiramente porque a mesmidade heideggeriana não corresponde à simples lógica da identidade. Em segundo lugar porque a leitura lacaniana do gozo, com a qual Žižek se fundamenta para criticar o "logocentrismo" de Heidegger, é passível, ela mesma, de ser acusada de logocêntrica - ou, mais precisamente, de falocêntrica.

Entremos na questão do não-todo na qual se baseia Žižek (em seu artigo), cuja referência está nas fórmulas da sexuação do Seminário 20 de Lacan, e de onde se enfatiza a asserção de um não-todo fundamental da psicanálise: "nem tudo é lógos". O lógos é não-todo pois, em suas palavras, a linguagem é corroída e mutilada interiormente por antagonismos e rupturas, nunca completamente ela mesma (Žižek, 2009, p.12). Leitura bastante precisa de Lacan que ressalta mais di- 
retamente o vetor masculino das posições assinalada nas fórmulas da sexuação. Pois nessas formas de se enunciar a incompletude do sujeito a partir de sua relação impossível com o objeto a ("o gozo do sujeito é não-todo", "o simbólico é não-todo", "o lógos é não-todo" etc.), o que encaramos é a castração própria à estrutura da fantasia e de um gozo todo ele em função do Falo (Lacan, 2008, p.14). Ocorre, contudo, da novidade trazida no Seminário 20 tratar-se justamente de um "não-todo" por outra via, a da nebulosíssima posição "feminina".

A partir de Encore, conjunto dos seminários proferidos de 1972 a 1973, a ideia freudiana do primado do Falo para os dois sexos é em parte mantida e em parte subvertida por Lacan. Isso se dá pela pluralidade que o autor concede ao conceito de gozo. Desenha-se em um quadro as modalidades de gozo correlatas às relações que o homem (\$) e a mulher ( $(\mathbb{A})$ estabelecem com objeto $a(\mathrm{a})$, com o Falo $(\Phi)$ e com uma enigmática Abertura indizível para além da linguagem $(S(A))$. Diz Lacan sobre suas notações: "Tais são as únicas definições possíveis da parte dita homem ou bem mulher para o que quer que se encontre na posição de habitar na linguagem" (Lacan, 2008/1972-1973, p. 86):

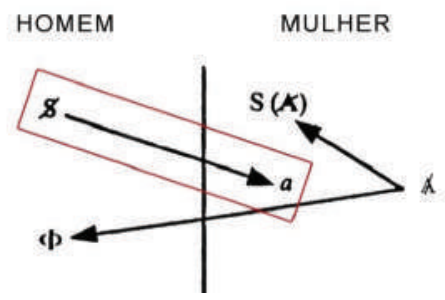

Figura 1. Quadro da sexuação reduzido com o friso nos símbolos presentes no matema da fantasia. Fuente:

Pelos símbolos inscritos no quadro da lógica da sexuação, a máxima lacaniana de que não há relação sexual entre homem e mulher se articula pela impossibilidade de se escrever um vetor de complementação de gozo entre as posições de $A$ (mulher) e $\$$ (homem), ou seja, de que afinal de contas não há relação entre $\$ \rightarrow a$, mas também de que não há relação entre $\$ \rightarrow \mathbb{A}$. Isso porque, para Lacan, o sujeito não goza do Outro sexo - ou, como afirma Žižek, não há injunção entre sujeito e gozo, ou entre sujeito e ser. Observamos Lacan sugerir que se a "mulher" se duplica entre a possibilidade de um gozo fálico e Outro 
para além do Falo, já a posição sexual masculina estaria toda ela em função fálica, isto é, totalmente circunscrita pela fantasia e limitada pelos efeitos de significação. $\mathrm{O}$ homem nesta perspectiva, portanto, diz respeito a uma posição de sujeito que reduz o Outro ao objeto $a$ na medida em que goza não com o Outro sexo, e sim com o seu inconsciente, mediante uma representação do ser absente (Falo). Interessa-nos com isso ressaltar: a posição masculina de gozo seria falocêntrica por excelência. E no sentido de sua adesão total à função significante, logocêntrica, pois totalmente mediada pelo logos na experiência de "ser".

Como bem nos relembra Žižek a respeito de Lacan, a experiência do ser pela linguagem se revelaria, paradoxalmente, como uma falta-a-ser. Em outras palavras, o ser do sujeito é para Lacan a sua falta-a-ser (objeto $a$ ), isto é, o próprio espaço vazio em meio à moradia simbólica.

E seria concebível nesta teoria psicanalítica uma experiência do ser falante para mais além do logos? Lacan surpreende ao sugerir que além desse gozo pensante neurótico (Lacan, 2008/1972-1973, p.77), haveria a possibilidade de se gozar pela via da ex-sistência:

Há um gozo dela, desse ela que não existe e não significa nada. Há um gozo dela sobre o qual talvez ela mesma não saiba nada a não ser que o experimenta [qu'elle l'éprouve] - isto ela sabe. Ela sabe disso, certamente, quando isso acontece [quand ça arrive]. [...] Esse gozo que se experimenta e do qual não se sabe nada, não é ele o que nos coloca na via da ex-sistência? E por que não interpretar uma face do Outro, a face Deus, como suportada pelo gozo feminino? (pp.80-82, itálico nosso).

Esse incompreensível gozar da ex-sistência abriria inclusive um novo modo de pensar psicanaliticamente sobre "Deus": não apenas como uma fantasia de suporte e complementação Simbólica própria da ilusão de salvação do sujeito de seu desamparo constitutivo. Longe de representar uma completude simbólica, o "Deus feminino" ou "místico", por assim dizer, realizaria o desamparo do ser falante a partir de um vazio transbordante, para mais além das identificações de um sujeito. O desamparo místico vivificaria um gozo a mais possível somente num evento de radical indeterminação imaginária e simbólica, e jamais mediante uma fantasia de completude de ser. $\mathrm{O}$ gozo imediato (sem mediações fálicas) do "Deus feminino", contudo, 
escaparia da condição de sujeito. Ou seja, aqui alcançaríamos uma inusitada tese na teoria lacaniana: o ser falante é não-todo sujeito, goza falicamente, mas também poderia gozar do ser ex-sistente.

O gozo, enquanto sexual, é fálico, quer dizer, ele não se relaciona ao Outro como tal (Lacan, 2008/1972-1973, p. 16).

Mas, o ser, é o gozo do corpo, como tal, quer dizer, como assexuado (p. 14).

(...) a mulher é aquilo que tem relação com esse Outro. (p. 77).

Mas se o sujeito não se relaciona com o Outro como tal, como compreender a estranha relação hetero-assexual do ser falante "feminino" com o Outro, simbolizada como $A \rightarrow S(A)$ ? Uma passagem de Lacan que se mostrará especialmente paradigmática neste sentido:

(...) o impasse que consiste em que elas se "mesmam" no Outro, pois enfim não é necessário de se saber Outro para sê-lo, uma vez que lá onde a alma encontra ser, diferencia-se a mulher, e disso se origina: difamam-na [homofonia na língua francesa entre "diz mulher" e "difama"]. (Lacan, 1972-1973, tradução livre nossa).

Lacan afirma que não há necessidade de se saber (simbolizar o) Outro para sê-lo. Não há necessidade de um assentamento representativo para ser Outro, do que entendemos: ser Outro é gozar desse Outro. Articula-se aí uma relação de mesmidade - ser o mesmo - entre a "mulher" e o seu gozo mais próprio. A "mulher", ou o "místico", surpreendentemente atenta para a lacuna indeterminável do Outro e, lá, passa a ser - passa a gozar - para além do objeto e de modo indizível (daí essa quase poesia de dizer que "a alma encontra ser"). Ali ela se diferencia, isto é, goza da diferença entre o Falo e o ser. A nova conjuntura de ser acessada pelo místico, portanto, já não é aquela do "ser faltante" às voltas com a representação de um objeto do desejo, impossível em sua dimensão real, e que apenas se positiva enquanto fantasia.

Num processo de indeterminação imaginária e simbólica própria desse novo gozo, o efeito em jogo seria o de abrir um espaço vazio nas identificações de objeto: uma abertura às inconsistências da fan- 
tasia, dentre elas o próprio dentre elas o próprio objeto Eu com sua bagagem de identificações biográficas. Pois se na teoria da fantasia é a ausência de um território do ser (objeto a) que causaria a criação de mapas simbólico-imaginários pelos quais erra um sujeito, já a experiência do ser êxtimo $S(\mathbb{A})$ estaria radicalmente para além da estrutura psíquica eu-quero-ser, isto é, não corresponderia ao território de mapa imaginário-simbólico nenhum. Trata-se de Outra coisa, não-identificável: “(...) ele (a) nos fará tomá-lo por um ser, em nome de ser aparentemente alguma coisa mesmo. Mas ele só se resolve, no fim das contas, em seu fracasso, em não poder sustentar-se na abordagem do real" (Lacan, 2008/1972-1973, p.102).

Enquanto a relação da mulher com o Outro se demonstraria uma relação de ser, isto é, de gozo, aquela relação do sujeito com seus semblantes seria a de gozar da falta-a-ser constitutiva do Outro. E ficamos assim diante da distinção entre a concepção de Outro como lugar da cadeia significante, e Outro como "consistência real além da dimensão simbólica" (Hamon, 2010, p. 239). Consideramos então que, onde se duplica a modalidade de gozo, em Lacan, duplica-se também a apreensão do ser (être): o ser indizível do gozo êxtimo $S(\AA)$, e o ser da significância enquanto gozo fálico, sexual, marcado no quadro pelo objeto $(a)$. A questão do ser se desdobra então entre ser da significância e ser indizível - entre duas modalidades de gozo.

E a favor dessa tese - na psicanálise lacaniana o ser do ser falante é o gozo -, lembremos que Lacan já a enunciava direta ou indiretamente pela relação de equivalência entre as expressões falta-a-ser e falta-a-gozar (manque-à-être e manque-à-jouir). A única substância que se possa atribuir ao ser, pela psicanálise lacaniana, seria então a substância do gozo. O que defendemos assim é o seguinte: em Encore, $o$ ser não se reduz ao objeto a, mas se remete também ao real do corpo que tanto precede quanto excede a moradia significante de um sujeito às voltas com sua falta. Para além do gozo fálico, consideramos então essa vertente do gozo feminino, o gozo místico do ser.

$\mathrm{S}(\AA)$ em vez de $a$, eis a grande diferença em jogo na não relação sexual: a mulher se "mesma" com o Outro no sentido de ser jogada numa enigmática experiência a mais de ser, em si mesma e para além 
de si mesma, tão improvável quanto necessariamente distinta do que se poderia imaginar. O que se passa no êxtase místico é indizível, difere contundentemente do complemento amoroso via objeto da fantasia. E não seria algo disso que o místico indiano Jiddu Krishnamurti [1895-1986] arriscava dizer em seus escritos poéticos e suas inúmeras palestras filosóficas?

Benção arrasadora, aquele raro fenômeno simplesmente existia, indiferente a qualquer forma de crítica ou avaliação. Fato inédito, sem conexão, no passado ou no futuro, era inacessível ao pensamento e nada representava em termos de ganho ou de lucro pessoal. Mas, por ser gratuita, dela jorrava a imensidão do amor e da beleza (Krishnamurti, 2004/1961, p.104, 105).

A ruptura de um princípio de identidade auto-afirmativa, concomitante ao acesso sem mediações a uma experiência temporária de ser ilimitado, inexprimível pelo pensamento, é também amplamente desenvolvida no trabalho do filósofo e místico russo Pavel Florenski [1882-1937], em cuja obra encontramos o pensamento da condição translógica do ser místico:

Os mistérios da religião [refere-se à experiência mística] não são segredos que não convém divulgar, não são senhas de conjurados. São experiências inexpressáveis, indizíveis, indescritíveis, que não podemos revestir de palavras de outro modo que não seja em forma de contradições, as quais são ao mesmo tempo "sim" e "não". Se dão conta aqui 'todos os mistérios... que ultrapassam o pensamento' (Florenski, 2010/1914, p.161)

Por fim, não nos passa desapercebido que Žižek resuma a questão do gozo (e do ser) a uma exclusiva mirada ao objeto impossível. A questão do gozo "místico" é para Žižek uma espécie de ode neurótica às psicoses, ou um fetiche capitalista de complementação de gozo; em suma, a modos de "alienações". Na questão do gozo, Žižek nos parece assim um comentador "todo ele fálico" da obra de Lacan, engajado numa escuta "toda ela fálica" da cultura. Assim sendo, há de se questionar se o autor não estaria cumprindo uma função de habilidoso pensador hiperfálico, no sentido lacaniano do termo, espécie de determinador do gozo impossível do Outro em termos de meras, 
perversas e irresponsáveis aspirações de autossuficiência do sujeito contemporâneo. Sintomático dessa leitura unidimensional de Žižek, sobre a questão do gozo, é justamente a sua escrita sobre o seminário Encore presente não apenas no artigo citado como também em seu livro $O$ amor impiedoso, em que nada se menciona além do gozo fálico. Uma estranha vista grossa de Žižek, bom leitor de Lacan, a qualquer consideração de um gozo "na via da ex-sistência". A única apreensão possível de ser, assim, dar-se-ia pela relação do sujeito com as representações fálicas e logocêntricas de sua extimidade.

Mas se Žižek trava a sua importante batalha contra a hegemonia do discurso capitalista, essa forma de discurso, como ele coloca, determinadora da impossibilidade da revolução político-social, por outro lado, Žižek não deixa de se posicionar de maneira análoga ao determinar o impossível de uma experiência de ser para além do objeto. Nesse caso, lancemos o que haja de "revolucionário" ou "amoroso" na experiência do gozo, então da ordem de um (im)possível, à mesma perspectiva do pensamento žižekiano sobre a impossibilidade do amor e da revolução:

(...) o "Real como impossível" significa, aqui, que o impossível acontece, que "milagres" como o Amor (ou a revolução política: "em alguns aspectos, uma revolução é um milagre", disse Lenin em 1921) de fato ocorrem. Do "impossível de acontecer", passamos, assim, ao "impossível acontece" - isso e não o obstáculo estrutural que adia para sempre a resolução final, é a coisa mais difícil de aceitar: "Nós esquecemos como ficar prontos para que até milagres aconteçam". (Žižek, 2012, p.140).

Amém!

\section{Referências bibliográficas}

Florenski, P. (2010/1914). La columna y el fundamento de la verdad. Salamanca, España: Sígueme.

Hamon, R. (2010). Jouissance et position féminine. In : Les fondamentaux de la psychanalyse lacanienne : repères épistémologiques, conceptuels et cliniques. Rennes, Francia: Presses Universitaires de Rennes. 
Heidegger, M. (1969/1955). Sobre o problema do Ser. Em Ernildo Stein (Trad.). São Paulo, Brasil: Livraria Duas Cidades.

Heidegger, M. (1983/1949). Sobre o "humanismo". Em Ernildo Stein (tradução, introduções e notas), Conferências e escritos filosóficos (pp.149-175). São Paulo, Brasil: Abril Cultural.

Heidegger, M. (1983/1957). Identidade e diferença. Em Ernildo Stein (tradução, introduções e notas), Conferências e escritos filosóficos (pp.177-202). São Paulo, Brasil: Abril Cultural.

Heidegger, M. (1983/1962). “Tempo e ser". Em Ernildo Stein (tradução, introduções e notas), Conferências e escritos filosóficos (pp.256-293). São Paulo, Brasil: Abril Cultural.

Heidegger, M. (2002/1950). A coisa. Em Emmanuel Carneiro Leão (Trad.), Ensaios e conferências. Petrópolis, Brasil: Editora Vozes.

Heidegger, M. (2003/1959). A essência da linguagem. Em A Caminho da linguagem. Petrópolis, Brasil: Editora Vozes.

Heidegger, M. (2006/1959-1969). Seminários de Zollikon. Petrópolis, Brasil: Editora Vozes.

Heidegger, M. (2009/1927). Ser e tempo. Em Márcia Sá Cavalcante Schuback (Trad.). Petrópolis, Brasil: Editora Vozes.

Krishnamurti, J. (2004/1961). Diário de Krishnamurti. Trad: Alexandra Trifler. São Paulo: Editora Pensamento-Cultrix.

Lacan, J. (1972-1973). Le séminaire: Livre 20: Encore. Staferla, disponível em: http://staferla.free.fr/.

Lacan, J. (2008/1972-1973). O Seminário. Livro 20: Mais, ainda. Rio de Janeiro, Brasil: Jorge Zahar Ed.

Sloterdijk, P. (1992). Regras para o parque humano. Rio de Janeiro, Brasil: Tempo Brasileiro.

Sloterdijk, P. (2009). Esferas I (Microsferología) - Borbujas. Madrid, España: Biblioteca de Ensayo Siruela.

Žižek, S. (2009). Por que Lacan não é heideggeriano. Em Lucas Mello Carvalho Ribeiro (Trad.). Belo Horizonte, Brasil: Scriptum.

Žižek, S. (2012). O amor impiedoso (ou: Sobre a crença). Em Lucas Mello Carvalho Ribeiro (Trad.). Belo Horizonte, Brasil: Autêntica. 